Since you have chosen to reject this paper even after amendment and since you cannot publish my raw data I am wondering if you will extend to me the courtesy of your columns to ask for the "evidence" on which the committee's report and your leading article are based. Meanwhile, for anyone who wants it, my data are on file in the Communicable Diseases (Scotland) Unit at Ruchill Hospital. Our article will be submitted for information and publication in other quarters.

There is a further point of immediate importance. Because of continuing doubts and lack of "evidence" about the safety and efficacy of immunisation against whooping cough, immunisation of children is declining sharply. The decline is most marked in districts where, according to our "evidence," the risk of contracting infection is highest. Unfortunately, in parallel with diminishing use of pertussis vaccine there is a fall in other forms of immunisation in childhood possibly because unanswered questions about pertussis vaccine are discouraging routine immunisations against diphtheria, poliomyelitis, and tetanus. For this reason also I trust that the "evidence" on which you clearly rely will not be unduly delayed in finding its way into your columns.

GORDON T STEWART

Department of Community Medicine,

University of Glasgow

\section{The problem of rosacea}

SIR,-It is true that, as reported in your leading article (15 November, p 366) I "took on the task of critically re-examining the main ideas in the light of [my] experience of 92 patients with rosacea; none could be supported." However, while agreeing that "there are still vacancies in the cowshed," would point out that you made no reference to a suggestion that I have made previously as to a potential new occupant.

We have pointed out ${ }^{1}$ that the upper dermis in rosacea is quite abnormal and shows evidence of both solar elastotic degeneration considerably in advance of what might reasonably be expected for a group of middle-aged Britishers and other dystrophic changes that are not easily categorised. Autoradiographs after injection of tritiated thymidine and enzyme histochemical tests have suggested ${ }^{2}$ that small dermal blood vessels are also involved in rosacea (probably secondarily). It is my belief, based on these findings, that the primary disorder is a dermal dystrophy resulting from "weathering" (sun, wind, and cold) and an inherent susceptibility to this process. The dermal attenuation produced in this way causes lack of dermal support for the subpapillary venous plexus, allowing these channels (and neighbouring lymphatics) to dilate enormously. The flushing seen in rosacea is in all probability the result of the vessel dilatation-not its cause. The dilated vessels could become incompetent in addition as a result of the persistent and extreme pooling seen in them and this in turn may lead to diffusion of injurious macromolecules and mediators of the inflammatory process into the dermis. This hypothetical process may be summarised in the diagram.

I would not wish the above suggested "occupant of the cowshed" to become a sacred cow. However, there is sufficient evidence for this hypothesis to be further tested and I hope that this letter will stimulate the cow's dissection rather than its perpetual milking.

Department of Medicine

University Hospital of Wales,

1 Marks, R, et al, Archives of Dermatology, 1969, 100, 683.
- Marks, R, Proceedings of the Royal Society of

\section{Plasma free fatty acids and ventricular} fibrillation

SIR,-Dr C A Sykes and his colleagues (27 December, p 735) report the relationship between plasma free fatty acid (FFA) concentrations in 23 diabetic and 24 nondiabetic patients with myocardial infarction and the incidence of ventricular fibrillation (VF). They showed that the plasma FFA levels were similar in diabetics who developed VF and in those who did not. But they are wrong in reaching the same conclusion for non-diabetics, as the following reassembly of their own data indicates.

\begin{tabular}{l|c|c}
\multicolumn{1}{c|}{ Patients } & $\begin{array}{c}\text { Mean plasma } \\
\text { FFA } \\
(\mathrm{mmol} 1)\end{array}$ & $\begin{array}{c}\text { Significance } \\
\text { of } \\
\text { difference }\end{array}$ \\
\hline $\begin{array}{l}\text { Non-diabetics with VF (5) } \\
\text { (19) }\end{array}$ & $\begin{array}{c}1 \cdot 76: 0.61 \\
1 \cdot 24 \div 0.40\end{array}$ & $\mathrm{P}<0.05$ \\
\hline $\begin{array}{l}\text { Diabetics with VF (5) } \\
\text { Diabetics without VF (18) }\end{array}$ & $\begin{array}{c}1.30 \div 0.59 \\
1.46 \pm 0.62\end{array}$ & $\begin{array}{l}\text { Not } \\
\text { significant }\end{array}$
\end{tabular}

The highest mean plasma FFA is in the subgroup of non-diabetics who developed VF and the concentrations considerably exceed the "threshold level" of about $1.2 \mathrm{mmol} / 1$, which approximates to a $2: 1$ molar binding ratio with albumin. Higher concentrations

elongiectasia + erythema + flushing

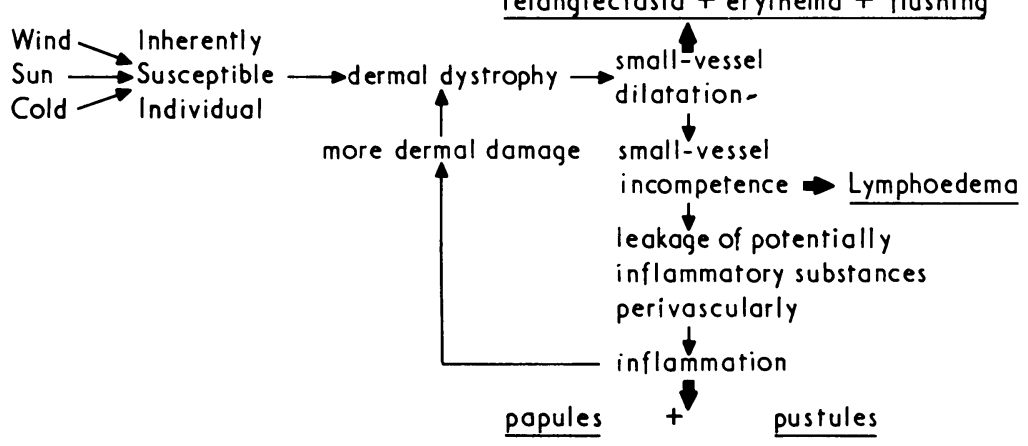

are associated with less firmly bound FFA and, as we showed ${ }^{1}$ and originally proposed, ${ }^{2}$ with a greater incidence of serious ventricular arrhythmias. Therefore I regard the findings of $\mathrm{Dr}$ Sykes and his colleagues as contradicting one of their own conclusions and, at the same time, as additional supportive evidence to the other studies ${ }^{3-5}$ which have shown a positive correlation in nondiabetic patients with myocardial infarction between elevated plasma FFA or glycerol levels and ventricular arrhythmias.

The authors appear to be justified, however, in reaching their other conclusion that plasma FFA levels do not correlate with VF in diabetic patients. Why should this be? One explanation might be that the mean plasma FFA concentrations were not very greatly elevated in these particular patients at a mean level of $1.30 \mathrm{mmol} / 1$. Another might be that the ischaemic myocardium is partly protected from the adverse effect of high plasma FFA because of the relatively high intracellular glucose concentrations likely to be present, particularly in those receiving insulin. The same authors ${ }^{6}$ have previously shown that VF is less common in insulin-treated diabetics compared with these on oral drugs but, unfortunately, it is not possible to determine from the recent report whether the five diabetics who developed VF were on insulin or oral drugs.

Department of Cardiology,

M F Oliver

Roval Infirmary,

dinburgh

Oliver. M F, Kurien. V A, and Greenwood, T W, Lancet, 1968, 1, 710

Kurien, V A, and Oliver, M F, Lancet, 1970 1. 813

Gupta, D K, et al, Lancet, 1969, 2. 1209

Carlstrom, S, and Christensson, B. British Heart fournal, 1971, 33, 884.

Carlstrom, S, and Gustafion, A, British Heart Soler, N G, et al, Lancet, 1974, 1, 475.

\section{Dietary fibre: search for the facts}

SIR,-A letter from Mr C L Copeland, executive director of the Flour Advisory Bureau (15 November, p 404), was headed "Dietary fibre: search for the facts." Perhaps, as the reporter/producer concerned with the "recent BBC TV programme concerning food," I may be allowed to correct his facts.

$\mathrm{Mr}$ Copeland said that "once again, in a recent $\mathrm{BBC} \mathrm{TV}$ programme concerning food, a commentator has had no hesitation in linking a list of serious diseases, including cancer of the colon, 'with all that lost fibre,' singling out white bread critically and claiming that some consumers have to obtain their fibre from a certain (named) proprietary pharmaceutical product." I am sure your readers will be able to make up their minds as to the correctness of $\mathrm{Mr}$ Copeland's synopsis if I quote what I did say.

The context of the programme was a comparison between 1875 (the date of the first effective food and drugs Act) and 1975. I said "compared to a century ago, the amount of roughage we get from bread has dropped dramatically, down to only one-sixth. That's the roughage that comes from the fibre of the wheat grain." Then came a sequence illustrating the baking of traditional white bread and comparing its water content with that of a modern plant-baked loaf.

I then said: "and what about all that lost fibre? There is a growing medical theory- 